\title{
Impact of chlortetracycline and sulfapyridine antibiotics on soil enzyme activities**
}

\author{
Ali Molaei ${ }^{1}$, Amir Lakzian ${ }^{1}$, Rahul Datta ${ }^{2,3}$, Gholamhosain Haghnia ${ }^{1}$, Alireza Astaraei ${ }^{1}$, \\ MirHassan Rasouli-Sadaghiani ${ }^{4}$, and Maria T. Ceccherini ${ }^{5}$ \\ ${ }^{1}$ Department of Soil Science, Faculty of Agriculture, Ferdowsi University of Mashhad, Mashhad, Iran \\ ${ }^{2}$ Department of Geology and Soil Science, Faculty of Forestry and Wood Technology, Mendel University, Czech Republic \\ ${ }^{3}$ School of Environment and Natural Resources, Ohio State University, United States \\ ${ }^{4}$ Department of Soil Science, Faculty of Agriculture, Urmia University, Urmia, Iran \\ ${ }^{5}$ Department of Agrifood Production and Environmental Sciences, University of Florence, Florence, Italy
}

Received June 21, 2017; accepted October 13, 2017

\begin{abstract}
Pharmaceutical antibiotics are frequently used in the livestock and poultry industries to control infectious diseases. Due to the lack of proper guidance for use, the majority of administrated antibiotics and their metabolites are excreted to the soil environment through urine and feces. In the present study, we used chlortetracycline and sulfapyridine antibiotics to screen out their effects on dehydrogenase, alkaline phosphatase and urease activity. Factorial experiments were conducted with different concentrations of antibiotic $\left(0,10,25\right.$ and $100 \mathrm{mg} \mathrm{kg}^{-1}$ of soil) mixed with soil samples, and the enzyme activity was measured at intervals of 1, 4 and 21 days. The results show that the chlortetracycline and sulfapyridine antibiotics negatively affect the dehydrogenase activity, but the effect of sulfapyridine decreases with time of incubation. Indeed, sulfapyridine antibiotic significantly affect the alkaline phosphatase activity for the entire three-time interval, while chlortetracycline seems to inhibit its activity within 1 and 4 days of incubation. The effects of chlortetracycline and sulfapyridine antibiotics on urease activity appear similar, as they both significantly affect the urease activity on day 1 of incubation. The present study concludes that chlortetracycline and sulfapyridine antibiotics have harmful effects on soil microbes, with the extent of effects varying with the duration of incubation and the type of antibiotics used.
\end{abstract}

Keywords: alkaline phosphatase, chlortetracycline, dehydrogenase, sulfapyridine, urease

\section{INTRODUCTION}

The intensive use of pharmaceutical antibiotics has become a common modern practice in animal husbandry for treating infectious diseases or for promoting animal

*Corresponding author e-mail: lakzian@um.ac.ir

**This work was supported by Ferdowsi University of Mashhad, Iran, and the Department of Geology and Soil Science, Mendel University in Brno, Czech Republic. growth (Ji et al., 2009; Sarmah et al., 2006). Due to lack of proper guidance for use, many antibiotics and their derivatives (i.e. chlortetracycline, sulfapyridine, sulfadiazine, oxytetracycline and tetracycline) are excreted in large quantities as active compounds into the environment (Ding and He, 2010; Kim et al., 2011; Nelson et al., 2011). Indeed, a considerable proportion of antibiotic gets into the soil structure after the contaminated manure is used to fertilize agricultural soils. Although antibiotic residues will undergo biological and physicochemical transformations, these compounds still act as antimicrobial agents, and they have a potentially toxic effect on the favourable bacteria and other organisms in the environment, affecting soil health (Baguer et al., 2000). These effects include:

- contamination of ground and sub-surface waters and soils;

- phylogenetic structure alteration and resistance expansion;

- damage to the microbial community and to terrestrial, as well as aquatic ecosystems functions; and

- adverse health effects in humans, plants and livestock (Mojica and Aga, 2011).

In Europe, complexes of tetracyclines (TCs) and sulfonamides (SAs) are commonly utilized as veterinary antibiotics (García-Galán et al., 2008; Schauss et al., 2009). Residues of such pharmaceuticals have already been discovered in soils in concentrations up to $300 \mathrm{ng} \mathrm{g} 1$ for tetracyclines and $11 \mathrm{ng} \mathrm{g} 1$ for sulfonamides (Hamscher et al.,

(C) 2017 Institute of Agrophysics, Polish Academy of Sciences 
2002; Höper et al., 2002). Tetracyclines can affect a large variety of microorganisms, such as aerobic, anaerobic, gram-positive, gram-negative bacteria (Liu et al., 2015); while sulfonamides hinder the synthesis of dihydropteroate in the direction of folic acid, which results in a reduced bacteria reproduction level (Demoling et al., 2009). Therefore, these antibiotics pose a potential ecological and environmental risk to soil microbial activities.

Soil enzyme activity is involved in nutrient cycling and the bioavailability of nutrients, and it may thus be used as an indicator of soil microbial function (Nannipieri et al., 2003). The total enzyme activity in the soil is a combination of the activities of accumulated enzymes (extracellular enzymes), such as urease and phosphatase, and enzymes of proliferating microorganisms (intracellular enzymes), such as dehydrogenase.

Anthropogenic activities, such as deposition of antibiotics in soil environment, may affect the amount and activity of soil enzyme at diverse functional levels which reduce plant growth and subsequent crop yield (Bansal, 2015). Therefore, the determination of soil enzyme activity is a potential bio-indicator for the analysis of the functional diversity of soil microbial communities because of its relation to soil enzymology (Yao et al., 2006). Moreover, the measurement of soil enzyme activity is a cultivation-independent method and can reflect the actual functioning of the entire microbial community.

In this study, chlortetracycline (CTC) and sulfapyridine (SPY) antibiotics were selected from the tetracyclines and sulfonamides groups, respectively, to investigate their effects on soil enzyme activities. The purpose of this study was (1) to determinate the concentration and time-dependent effects of these antibiotics on soil enzymes activities, and (2) to study the specific effects of two different antibiotics on soil enzyme activities.

\section{MATERIAL AND METHODS}

Soil sampling was randomly carried out from agricultural land, which had been used for alfalfa (M. sativa) cultivation for five years prior to sampling, located in the countryside of Urmia, Iran. In the experiment, soil samples were collected in black polythene bags from 1-20 $\mathrm{cm}$ of top soil. No biological or chemical fertilizers, or other organic materials, were added to this cropland within a decade preceding the sampling. Therefore, the probability of getting any trace of antibiotics in the soil was insignificant. The soil samples were sieved through a $2 \mathrm{~mm}$ particle sieve and then stored at $4^{\circ} \mathrm{C}$ in the dark for further use.

The physicochemical properties of soil samples were analyzed by using protocols described in the publication by Richards (1954). The soil texture was a sandy loam consisting of $52.35 \%$ sand, $29.23 \%$ silt and $18.42 \%$ clay. The $\mathrm{pH}$ value, total organic carbon and water holding capacity (WHC) were 7.56, 0.95 and 20\%, respectively.
The highly pure (>99\%) sulfapyridine and chlortetracycline antibiotics were obtained from Fluka and SigmaAldrich, respectively. The soil samples were prepared so as to contain four different level concentrations $(0,10,25$ and $100 \mathrm{mg} \mathrm{kg}^{-1}$ ) of CTC and SPY antibiotics. Since the concentration of the added antibiotics was very low, in order to obtain a homogenous antibiotic distribution in all soil samples, we first mixed the antibiotic with $10 \mathrm{~g}$ of preheated $\left(600^{\circ} \mathrm{C}, 48 \mathrm{~h}\right)$ soil. The antibiotic-mixed soil was then added to the $200 \mathrm{~g}$ dry weight of soil sample. Finally, the soil samples were placed in $500 \mathrm{ml}$ trays covered over with a cap containing many small holes to allow gas exchange and to minimize water evaporation. For the activation of soil microbial growth, $2 \mathrm{~g}$ of glucose per $1 \mathrm{~kg}$ of soil was added to the samples, and then the soil samples were incubated for 21 days in the dark, at $25^{\circ} \mathrm{C}$, to avoid the quick degradation of the antibiotics. The optimum moisture content $(50 \%$ of the field water capacity) was maintained throughout the incubation period. The same procedure was followed for the preparation of samples of four different concentrations.

Soil dehydrogenase activity (DHA) was determined in accordance with Casida Jr et al. (1964), by the application of colorimetric measurement of reduction of 2, 3, 5- triphenyltetrazolium chloride (TTC) to triphenyl formazan (TPF). Briefly speaking, $5 \mathrm{ml}$ of an aqueous TTC solution $(0.4 \%)$ and $5 \mathrm{ml}$ of $0.1 \mathrm{M}$ tris hydroxymethyl aminomethane $(\geq 99.8 \%$, Merck), adjusted with $\mathrm{HCl}(32 \%)$ to $\mathrm{pH} 7.4$, were added to $5 \mathrm{~g}$ of a soil sample in $30 \mathrm{ml}$ glass flasks; samples were then incubated for $24 \mathrm{~h}$ at $28^{\circ} \mathrm{C}$. For the blank sample, no TTC solution was added. The produced TPF was extracted with $25 \mathrm{ml}$ acetone through shaking for $2 \mathrm{~h}$ on a horizontal rotary shaker. Subsequently, the solution was filtered, and the TPF concentration was determined spectrophotometrically at $482 \mathrm{~nm}$. DHA was reported as micrograms TPF per gram (dw) $d^{-1}$.

The alkaline phosphatase activity was determined using the method which was previously described by RodriguezLoinaz et al. (2008). A reaction mixture consisting of $1 \mathrm{~g}$ fresh soil $(<2 \mathrm{~mm}), 0.2 \mathrm{ml}$ of toluene, $1 \mathrm{ml}$ of p-nitrophenyl phosphate solution and $4 \mathrm{ml}$ of modified universal buffer (MUB, pH 11) was incubated at $37^{\circ} \mathrm{C}$ for $1 \mathrm{~h}$. After the incubation, the reaction was stopped by adding $1 \mathrm{ml}$ of $\mathrm{CaCl}_{2} 0.5 \mathrm{M}$ and $4 \mathrm{ml}$ of $\mathrm{NaOH} 0.5 \mathrm{M}$. The soil solutions were then filtered through a Whatman filter paper (42 pore size), and the yellow color intensity of the filtrates was measured spectrophotometrically at $410 \mathrm{~nm}$.

The urease enzyme activity was determined using the steam distillation method as described by Mulvaney (1996) and Tabatabai (1994). Briefly speaking, $5 \mathrm{~g}$ of fresh soil samples $(<2 \mathrm{~mm})$ were mixed with $0.2 \mathrm{ml}$ of toluene, $9 \mathrm{ml}$ of tris (hydroxymethyl) aminomethane (THAM) buffer $(0.01 \mathrm{M}, \mathrm{pH}$ 9) and $1 \mathrm{ml}$ of a $0.2 \mathrm{M}$ urea solution as 
a substrate. The reaction mixture was subsequently incubated at $37^{\circ} \mathrm{C}$ for $2 \mathrm{~h}$. The released $\mathrm{NH}_{4}-\mathrm{N}$ from the urea hydrolysis was measured with a steam distillation apparatus.

Statistical analyses were performed using the SAS, 9.2 software. Microbial parameter data were analyzed using a two-way analysis of variance (ANOVA), with antibiotic concentration and incubation time acting as variance factors. Differences between means for a given antibiotic concentration and incubation times were compared using a one-way ANOVA and Fisher's LSD post-hoc test. The values were considered to be significantly different at a 95\% confidence level. The values in the figures correspond to the average of triplicate data \pm standard deviations (SD).

\section{RESULTS}

The DHA was determined during the incubation in soil samples treated with CTC and SPY (Fig. 1a). Herein, the DHA ranged from 4.56 to $14.23 \mu \mathrm{g}$ TPF $\mathrm{g}^{-1} \mathrm{~d}^{-1}$, and from 5.88 to $14.23 \mu \mathrm{g} \mathrm{TPF} \mathrm{g}^{-1} \mathrm{~d}^{-1}$ in soil samples treated with CTC and SPY, respectively. Changes in DHA in CTC treatments depended on the incubation time and antibiotic concentration. The DHA was highest at control treatment of day 1 and the lowest at 10,25 and $100 \mathrm{mg} \mathrm{kg}^{-1}$ of day 21 of incubation. The changes in the DHA in SPY treatments largely depended on the incubation time, and were the highest for the control treatment on day 1 and the lowest on day 21 of incubation. After day 1 of incubation, the DHA significantly $(\mathrm{p} \leq 0.05)$ decreased, with a simultaneous increase in CTC concentration, as compared to the control treatment. However, there was no significant difference in the DHA between 25 and $100 \mathrm{mg} \mathrm{kg}^{-1}$ treatments (Fig. 1a). In addition, the DHA was seen to decrease at lower values in different CTC concentrations, when compared to the control treatment over time. This could indicate that DHA was inhibited by the addition of CTC. Also, minimum DHA was found at higher CTC concentrations, which suggests that inhibition was more obvious at such concentrations.

In contrast to CTC, DHA was less affected by treatments with SPY. There was no significant difference $(p \leq 0.05)$ in the DHA values between $10 \mathrm{mg} \mathrm{kg}^{-1}$ and control treatments on day 1 of incubation (Fig. 1a). However, the lowest values of dehydrogenase activity were at the highest antibiotic concentration on day 1 . With the increase in incubation time to 4 days, the DHA was positively affected by the SPY treatment, as compared to the control treatment, which indicates that SPY had temporary tension on DHA on day 1 of incubation and the tension was later removed. However, there was no significant difference $(\mathrm{p} \leq 0.05)$ between all SPY treatments and the control treatment on day 21, which suggests that the SPY antibiotic does not exert an adverse effect on DHA.
The alkaline phosphatase (ALP) activity was determined in the soil samples treated with CTC and SPY. As shown in Fig. 1b, the ALP activity on the CTC treatments ranged from $183.83 \mu \mathrm{g} \mathrm{pNP} \mathrm{g}^{-1} \mathrm{~h}^{-1}$ on day 1 of incubation, to $565.48 \mu \mathrm{g} \mathrm{pNP} \mathrm{g}^{-1} \mathrm{~h}^{-1}$ on day 21 of incubation, which indicates the incubation time dependence. The ALP on SPY treatments ranged from $165.47 \mu \mathrm{g} \mathrm{pNP} \mathrm{g}^{-1} \mathrm{~h}^{-1}$ at $100 \mathrm{mg} \mathrm{kg}^{-1}$ treatment, to $388.04 \mu \mathrm{g} \mathrm{pNP} \mathrm{g}^{-1} \mathrm{~h}^{-1}$ at the control treatment, which indicates dependence on antibiotic concentration. Compared to the control treatment, a decrease in activity of ALP was observed in the soil samples treated with CTC antibiotic until day 4 of incubation. This effect indicates that CTC negatively affects soil alkaline phosphatase activity in the early days of incubation. On day 21 of incubation, ALP activity was increased $(\mathrm{p} \leq 0.05)$ at 25 and $100 \mathrm{mg}$ $\mathrm{kg}^{-1}$ treatments, in comparison with the effect indicated at $10 \mathrm{mg} \mathrm{kg}^{-1}$ and when compared with the control treatment. This shows that the addition of CTC antibiotic had positive effects on ALP activity over time. In contrast, there was a clear decline $(p \leq 0.05)$ in ALP activity with an increase in the concentration of SPY antibiotic, when compared to the control treatment during incubation. Nevertheless, this decrease was assuaged on day 21 as compared to day 1 of incubation. Overall, the ALP activity was very susceptible to SPY treatment, and the inhibition depended on antibiotic concentration. Indeed, the highest inhibition was observed on day 1 where ALP activity decreased by fifty-two percent in response to the addition of $100 \mathrm{mg}$ of SPY per $1 \mathrm{~kg}$ of dry soil. This inhibition continued until 21 day of incubation.

The enzyme activity of urease (URE) during the incubation time was determined in the soil samples treated with CTC and SPY (Fig. 1c). The CTC and SPY antibiotics significantly $(\mathrm{p} \leq 0.05)$ affected the urease activity on day 1 of incubation (Fig. 1c). However, the toxicity of CTC was higher than that of SPY, especially at higher antibiotic concentrations ( 25 and $100 \mathrm{mg} \mathrm{kg}^{-1}$ ). The URE activity of all antibiotic treatments and the control treatment of CTC and SPY antibiotics significantly $(p \leq 0.05)$ increased with an extension of incubation time. However, the urease activity significantly $(p \leq 0.05)$ decreased with the increasing concentration of CTC, as compared to the control treatment, on day 4 of incubation, while this biological parameter significantly increased on all SPY treatments. Furthermore, on day 21 of incubation, the URE activity of 10, 25 and $100 \mathrm{~m} \mathrm{~kg} \mathrm{k}^{-1}$ concentrations of these antibiotics significantly $(p \leq 0.05)$ decreased, as compared to the control treatment, which indicates that CTC and SPY antibiotics have prolonged effects on soil urease activity.

\section{DISCUSSION}

To clarify the impact of CTC and SPY antibiotics on soil microbial functions, the activities of dehydrogenase (DHA), alkaline phosphatase (ALP) and urease (URE) enzymes were measured (Fig. 1). The activities of DHA, 
a $\square 0 \mathrm{mg} \mathrm{kg}^{-1} \square 10 \mathrm{mg} \mathrm{kg}^{-1} \mathbf{\square} 25 \mathrm{mg} \mathrm{kg}^{-1} \square 100 \mathrm{mg} \mathrm{kg}^{-1}$

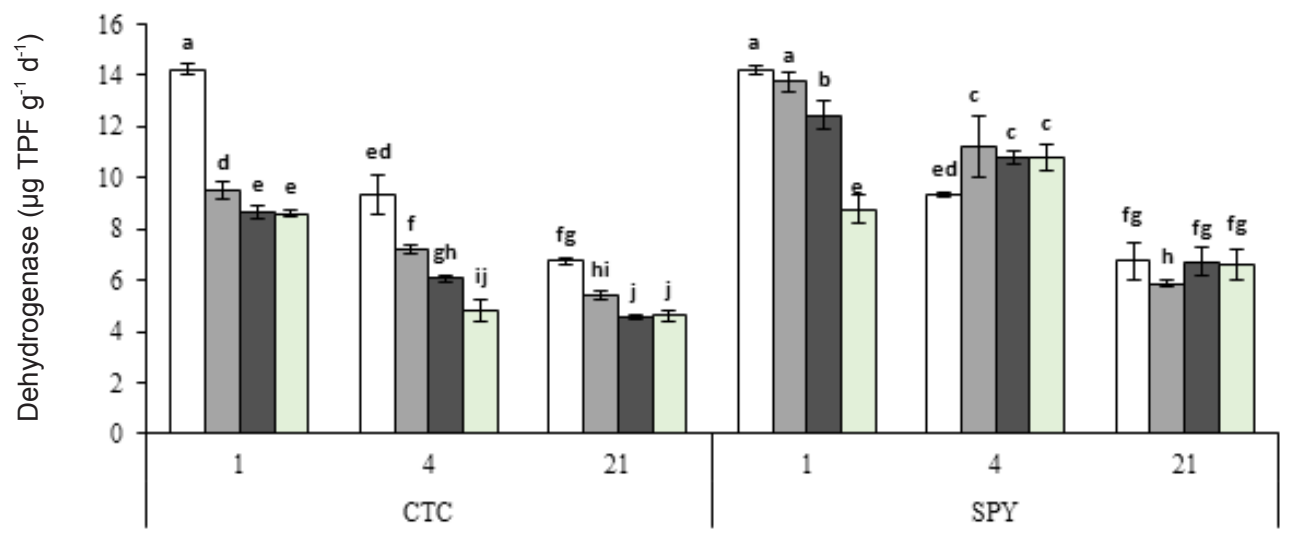

b

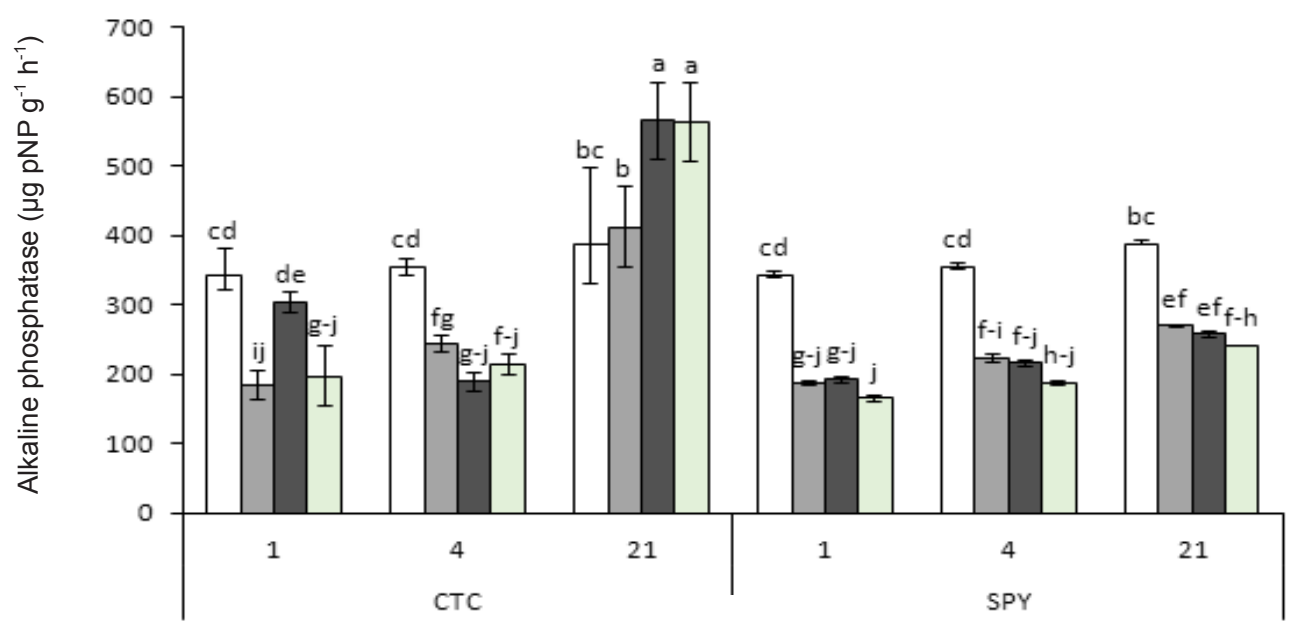

c

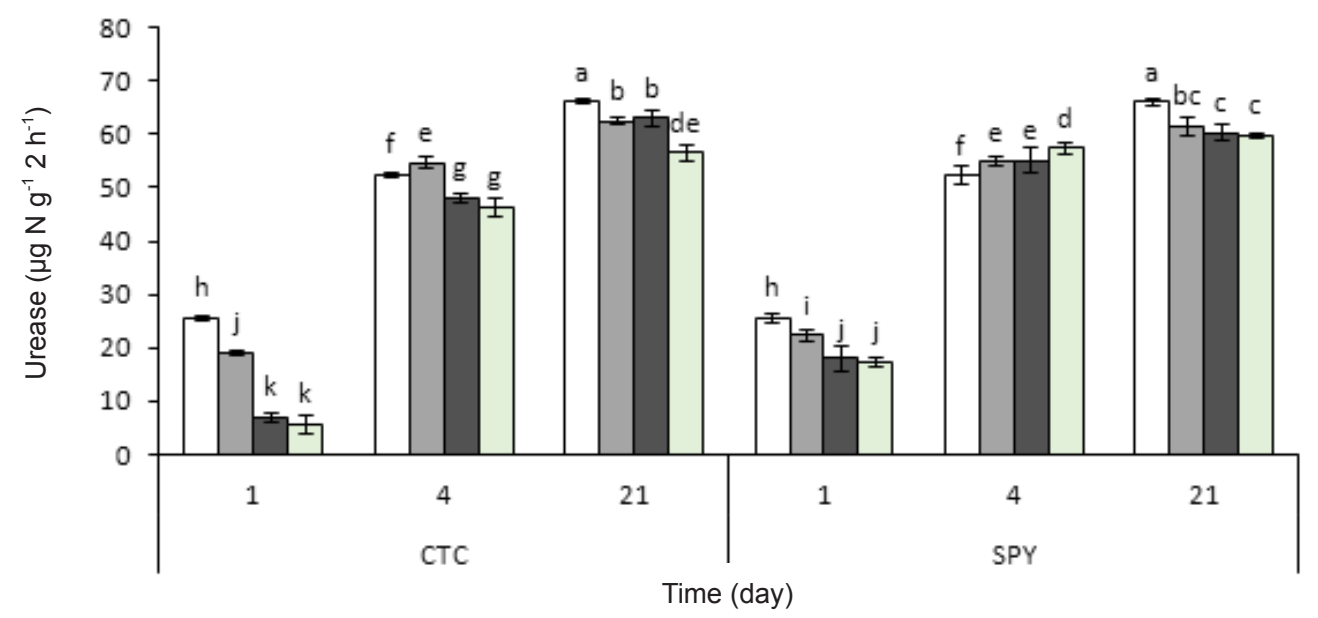

Fig. 1. The activity of: a - dehydrogenase, $b$ - alkaline phosphatase, and c - urease depending on sample treatment of CTC and SPY (spiking concentrations: $0,10,25$ and $100 \mathrm{mg} \mathrm{kg}^{-1}$ ) and incubation time (1, 4 and 21 days). The different letters indicate significant difference ( $95 \%$ confidence intervals) during incubation (one-way ANOVA, followed by the least significant difference test). Error bars represent the standard deviation of replicate analyses $(n=3)$. 
ALP and URE correlate with the oxidative activity, and the $\mathrm{P}$ and $\mathrm{N}$ cycles of soil microbiota in the environment, respectively (Liu et al., 2014).

Various studies have been reported that glucose or other organic substrates are helpful in activating soil microbial activities for observing the effects of veterinary antibiotics on soil microbial functions, such as enzymatic activities (Demoling et al., 2009; Hammesfahr et al., 2011; Liu et al., 2015; Qingxiang et al., 2009). In the present study, glucose as a substrate was co-applied with the CTC and SPY in order to amplify the activity of the soil microbiota.

It was revealed that chlortetracycline antibiotic adversely affected the DHA on day 1 and on day 4 of incubation (Fig. 1a). This is not a surprising result because CTC as a bacterial inhibitor may affect the soil microbial functions through the direct shift of the soil bacterial structure and the frequency of some bacterial functions (Bailey et al., 2003). What is more, the DHA significantly reduced at the CTC treatments, in comparison with the control treatment, on 21 days of incubation, but the effect of CTC on DHA was reduced, when compared to DHA on days 1 and 4 of incubation. Still, assuming that the CTC concentration may be partly adsorbed by the soil surface over time (Chander et al., 2005), we concluded that residual concentrations of this antibiotic might be high enough to exert undesirable effects on soil bacteria, and the growth of soil microflora was still under the influence of preliminary concentrations of this antibiotic. Reichel et al. (2013) observed that the antibacterial activity of sulfadiazine (SDZ) and difloxacin (DIF) antibiotics was maintained despite the gradual reduction in these compounds after 63 days of incubation. Thus, despite the residual concentrations of antibiotics having a low bioavailability in soils, these act as a long-term release source of antibiotics.

In contrast, the SPY antibiotic had an undesirable effect on soil dehydrogenase activity only at higher antibiotic concentrations on 1 day of incubation (Fig. 1a), while the DHA was increased at SPY treatments, compared to the control treatment, after 4 days of incubation. One important factor involved in the degradation of sulfonamide antibiotics in soils is the photo-degradation of these compounds (Baran et al., 2009). In the present study, the antibiotic treatments were incubated in the dark. Hence, the dissipation of SPY antibiotic was most probably low because of photodegradation. Nevertheless, Drillia et al. (2005) hold that the biodegradation of sulfonamide antibiotics is negligible. Therefore, the increase in DHA at SPY treatments, when compared to the control treatment, on day 4 was unclear at least in this study. However, there was no significant difference in DHA between the SPY and control treatments after 21 days. Still, in this study, the bioavailable concentrations of SPY antibiotics were not measured. Therefore, we do not expect that the similar bioavailability of antibiotic treatments is the reason for the obtained results. Nevertheless, the extractable concentrations of antibiotics, considered as bioavailable concentration, were probably reduced due to the sorption of antibiotics on soil particles (Kahle and Stamm, 2007), as well as due to the degradation and formation of non-extractable residuals (Heise et al., 2006). Our observations were in line with the findings of Boleas et al. (2005), in which soil enzyme activities were inhibited by antibiotics in the early days of incubation, and then recovered at the end of the experiment.

Phosphatase enzyme catalyzes the mineralization of phosphorous. This enzyme is mostly found in soil, and is used as an indicator of soil biological activity (Xiu-Mei et al., 2008).

In the early days of incubation (days 1 and 4), the ALP activity was significantly decreased at all CTC treatments, compared to the control treatment (Fig. 1b), which results from the CTC antibiotic being a broad spectrum antibacterial agent (Pinna et al., 2012). Our data were in line with those of Qingxiang et al. (2009). In their work, the OTC antibiotic was seen to adversely affect the alkaline phosphatase activity at soil at $\mathrm{pH} 7.8$, and ALP activity was reduced by 40 , and 64 , to $80 \%$, at $10 \mathrm{mg} \mathrm{kg}^{-1}$ and $30 \mathrm{mg} \mathrm{kg}^{-1}$ concentrations, respectively. The increase in ALP activity at higher CTC concentrations, as compared to lower concentrations on day 21 of incubation, might be due to a decrease in the extractable CTC fraction, as tetracycline antibiotics hold high potential for rapid adsorption on soil matrix, and thus for stabilization in free concentration. Liu et al. (2015) also found that the extractable concentration of CTC intensively decreased over time. In addition to the decrease in CTC bioavailability, the development of antibiotic resistant bacteria (Wu et al., 2010), as well as the release of bioavailable substrate from dead microbial biomass, might mask the antibacterial activity of CTC (Widenfalk et al., 2004).

In contrast to the CTC antibiotic, the SPY antibiotic significantly decreased the ALP activity at all concentrations of antibiotic, compared to the control treatment. This reflects the longer effects of this antibiotic on soil alkaline phosphatase activity. Adsorption coefficients of sulfonamides in the range of $\mathrm{pH} 4$ to $\mathrm{pH} 8$ depend on soil $\mathrm{pH}$, due to the amphoteric properties of these compounds. In acidic $\mathrm{pH}$, sulfonamides have a positive or neutral charge, while at neutral and alkaline $\mathrm{pH}$, charges on these are negative (Park and Huwe, 2016). In our study (soil pH 7.80), sulfonamides have a negative charge, and this results in a decreased adsorption coefficient. Therefore, SPY antibiotic become less adsorbed by the soil particles, thus resulting in adverse effects on soil functional activity such as alkaline phosphatase activity (Hamscher et al., 2005). Another important factor that retains the adverse effects of SPY during the incubation process might be the high resistance of this antibiotic to biodegradation (Drillia et al., 2005; Kümmerer et al., 2004). Indeed, Al-Ahmad et al. (1999) observed weak biodegradability of sulfamethoxazole (SMX) on day 28 of incubation. The weak degradation of 
sulfonamides, therefore, could contribute to the inhibition of microorganism activity due to high primary concentrations of antibiotics (Zhang et al., 2013).

The overall changes in the urease activity that had a close correlation with the soil $\mathrm{N}$ cycle were, in our study, seen in soil samples treated with CTC and SPY antibiotics (Fig. 1c), and it is noticeable that both CTC and SPY antibiotics significantly affected urease activity on day 1 of incubation. However, the adverse effect of CTC was more significant than that of SPY, indicating the higher toxicity of CTC on soil microbial activity. In this regard, Thiele-Bruhn (2005) showed that the toxicity of tetracycline antibiotics was slightly bigger than that of sulfonamides antibiotics. However, in our work, the URE activity was considerably enhanced by treatments of CTC and SPY antibiotics on day 4 and day 21 days of incubation, which indicates that soil microflora could be using these antibiotics as a carbon source. These results were in line with the findings of Liu et al. (2015) who observed an increase in soil enzyme activity on soil samples treated with chlortetracycline and sulfonamides in the early days of incubation. However, the URE activity was significantly decreased at different concentrations of CTC and SPY (compared to the control treatment), indicating the inhibitory effects of these antibiotics on soil microbial functions. Similar results about the effects of antibiotics on enzyme activities have been reported by Thiele-Bruhn and Beck (2005), and by Pinna et al. (2012), and our results clarify the adverse effects of residual antibiotics on soil microbial communities.

In general, the effects of chlortetracycline (CTC) and sulfapyridine (SPY) antibiotics on dehydrogenase and alkaline phosphatase activities were different in the course of incubation, while the effects of these antibiotics on urease activity followed the same trend. These results suggest that the effects of pharmaceutical antibiotics on soil microbial functions depend on the soil microbial parameters determined and on the kind of antibiotic used.

In our study, the measurements of soil enzyme activities showed the undesirable effects of pharmaceutical antibiotics (CTC and SMX) on soil enzyme activities. However, in contrast to heavy metals, the effects of pharmaceutical antibiotics on soil biochemical activities cannot be assessed by one special method alone. For a comprehensive study of antibiotics on soil microbial communities, a combination of different bioassays must be used.

\section{CONCLUSIONS}

1. Chlortetracycline antibiotics adversely affect dehydrogenase activity, while sulfapyridine antibiotics have a transient adverse effect on dehydrogenase activity during incubation.
2. Alkaline phosphatase activity is differently affected by these two antibiotics; chlortetracycline antibiotic has a positive effect on alkaline phosphatase activity with increasing incubation time, while sulfapyridine antibiotic has a constant negative effect on the activity of this enzyme.

3 . The effects of chlortetracycline and sulfapyridine antibiotics on urease activity follow almost exactly the same pattern; chlortetracycline and sulfapyridine negatively affect the urease activity on day 1 of incubation. However, with increasing time, the adverse effect of chlortetracycline and sulfapyridine antibiotics decreases.

4. The present results indicate that the pharmaceutical antibiotics might exert undesirable effects on soil microbial functions, such as enzyme activities, depending on the microbial parameters considered and the kind of antibiotics used.

Conflict of interest: There is no conflict of interest between the authors.

\section{REFERENCES}

Al-Ahmad A., Daschner F.D., and Kümmerer K., 1999. Biodegradability of cefotiam, ciprofloxacin, meropenem, penicillin G, and sulfamethoxazole and inhibition of waste water bacteria. Arch. Environ. Contam. Toxicol., 37(2), 158-163.

Baguer A.J., Jensen J., and Krogh P.H., 2000. Effects of the antibiotics oxytetracycline and tylosin on soil fauna. Chemosphere, 40(7): 751-757.

Bailey V.L., Smith J.L., and Bolton H., 2003. Novel antibiotics as inhibitors for the selective respiratory inhibition method of measuring fungal: bacterial ratios in soil. Biol. Fertil. Soils, 38(3): 154-160.

Bansal O.P., 2015. Effects of tetracycline on soil enzyme activities in an alluvial soil. Br. J. Med. Med. Res., 5(8): 1007-1016.

Baran W., Adamek E., Sobczak A., and Sochacka J., 2009. The comparison of photocatalytic activity of Fe-salts, $\mathrm{TiO} 2$ and $\mathrm{TiO} 2 / \mathrm{FeCl} 3$ during the sulfanilamide degradation process. Catal. Commun., 10(6): 811-814.

Boleas S., Alonso C., Pro J., Fernández C., Carbonell G., and Tarazona J.V., 2005. Toxicity of the antimicrobial oxytetracycline to soil organisms in a multi-species-soil system (MS*3) and influence of manure co-addition. J. Hazard. Mater., 122(3): 233-241.

Casida Jr, L.E., Klein D.A., and Santoro T., 1964. Soil dehydrogenase activity. Soil Sci., 98(6): 371-376.

Chander Y., Kumar K., Goyal S.M., and Gupta S.C., 2005. Antibacterial activity of soil-bound antibiotics. J. Environ. Qual., 34(6): 1952-1957.

Demoling L.A., Bååth E., Greve G., Wouterse M., Schmitt H., 2009. Effects of sulfamethoxazole on soil microbial communities after adding substrate. Soil Biol. Biochem., 41(4): 840-848.

Ding C. and He J., 2010. Effect of antibiotics in the environment on microbial populations. Appl. Microbiol. Biotechnol., 87(3): 925-941.

Drillia P., Dokianakis S.N., Fountoulakis M.S., Kornaros M., Stamatelatou K., and Lyberatos G., 2005. On the occasional biodegradation of pharmaceuticals in the activated sludge process: the example of the antibiotic sulfamethoxazole. J. Hazard. Mater., 122(3): 259-265. 
García-Galán M.J., Díaz-Cruz M.S., and Barceló D., 2008. Identification and determination of metabolites and degradation products of sulfonamide antibiotics. TrAC Trends Anal. Chem., 27(11): 1008-1022.

Hammesfahr U., Kotzerke A., Lamshöft M., Wilke B.-M., Kandeler E., and Thiele-Bruhn S., 2011. Effects of sulfadiazine-contaminated fresh and stored manure on a soil microbial community. Eur. J. Soil Biol., 47(1): 61-68.

Hamscher G., Sczesny S., Höper H., and Nau H., 2002. Determination of persistent tetracycline residues in soil fertilized with liquid manure by high-performance liquid chromatography with electrospray ionization tandem mass spectrometry. Anal. Chem., 74(7): 1509-1518.

Hamscher G., Pawelzick H.T., Hoper H., and Nau H., 2005. Different behavior of tetracyclines and sulfonamides in sandy soils after repeated fertilization with liquid manure. Environ. Toxicol. Chem., 24: 861-868.

Heise J., Höltge S., Schrader S., and Kreuzig R., 2006. Chemical and biological characterization of non-extractable sulfonamide residues in soil. Chemosphere, 65(11): 2352-2357.

Höper H., Kues J., Nau H., and Hamscher G., 2002. Eintrag und Verbleib von Tierarzneimittelwirkstoffen in Böden. Bodenschutz, 4(2): 141-148.

Ji L., Chen W., Duan L., and Zhu D., 2009. Mechanisms for strong adsorption of tetracycline to carbon nanotubes: a comparative study using activated carbon and graphite as adsorbents. Environ. Sci. Technol., 43: 2322-2327.

Kahle M. and Stamm C., 2007. Time and pH-dependent sorption of the veterinary antimicrobial sulfathiazole to clay minerals and ferrihydrite. Chemosphere, 68(7): 1224-1231.

Kim K.-R., Owens G., Kwon S.-I., So K.-H., Lee D.-B., and Ok Y.S., 2011. Occurrence and environmental fate of veterinary antibiotics in the terrestrial environment. Water, Air, Soil Pollut., 214(1-4): 163-174.

Kümmerer K., Alexy R., Hüttig J., and Schöll A., 2004. Standardized tests fail to assess the effects of antibiotics on environmental bacteria. Water Res., 38(8): 2111-2116.

Liu B., Li Y., Zhang X., Wang J., and Gao M., 2015. Effects of chlortetracycline on soil microbial communities: Comparisons of enzyme activities to the functional diversity via Biolog EcoPlatesTM. Eur. J. Soil Biol., 68: 69-76.

Liu B., Li Y., Zhang X., Wang J., and Gao M., 2014. Combined effects of chlortetracycline and dissolved organic matter extracted from pig manure on the functional diversity of soil microbial community. Soil Biol. Biochem., 74: 148-155.

Mojica E.-R. and Aga D.S., 2011. Antibiotics pollution in soil and water: Potential ecological and human health issues. In: Encyclopedia of Environmental Health (Ed. J.O. Nriagu), University at Buffalo, Buffalo, NY, USA.

Mulvaney R.L., 1996. Nitrogen-inorganic forms. In: Sparks, DL editor. Methods soil Anal. part 3-Chemical methods. Soil Science Society of America, Madison, WL, 5: 1123-1184.

Nannipieri P., Ascher J., Ceccherini M., Landi L., Pietramellara G., and Renella G., 2003. Microbial diversity and soil functions. Eur. J. Soil Sci., 54(4): 655-670.

Nelson K.L., Brözel V.S., Gibson S.A., Thaler R., and Clay S.A., 2011. Influence of manure from pigs fed chlortetracycline as growth promotant on soil microbial community structure. World J. Microbiol. Biotechnol., 27(3), 659-668.
Park J.Y. and Huwe B., 2016. Effect of $\mathrm{pH}$ and soil structure on transport of sulfonamide antibiotics in agricultural soils. Environ. Pollut., 213(8): 561-570.

Pinna M.V., Castaldi P., Deiana P., Pusino A., and Garau G., 2012. Sorption behavior of sulfamethazine on unamended and manure-amended soils and short-term impact on soil microbial community. Ecotoxicol. Environ. Saf., 84: 234-242.

Qingxiang Y., Zhang J., Kongfang Z.H.U., and Zhang H., 2009. Influence of oxytetracycline on the structure and activity of microbial community in wheat rhizosphere soil. J. Environ. Sci., 21(7): 954-959.

Reichel R., Rosendahl I., Peeters E.T.H.M., Focks A., Groeneweg, J., Bierl R., Schlichting A., Amelung W., and Thiele-Bruhn S., 2013. Effects of slurry from sulfadiazine-(SDZ) and difloxacin-(DIF) medicated pigs on the structural diversity of microorganisms in bulk and rhizosphere soil. Soil Biol. Biochem., 62: 82-91.

Richards L.A., 1954. Diagnosis and improvement of saline and alkali soils. Agriculture Handbook, 60: 1-6.

Rodriguez-Loinaz G., Onaindia M., Amezaga I., Mijangos I., and Garbisu C., 2008. Relationship between vegetation diversity and soil functional diversity in native mixed-oak forests. Soil Biol. Biochem., 40(1): 49-60.

Sarmah A.K., Meyer M.T., and Boxall A.B.A., 2006. A global perspective on the use, sales, exposure pathways, occurrence, fate and effects of veterinary antibiotics (VAs) in the environment. Chemosphere, 65: 725-759.

Schauss K., Focks A., Heuer H., Kotzerke A., Schmitt H., Thiele-Bruhn S., Smalla K., Wilke B.-M., Matthies M., Amelung W., 2009. Analysis, fate and effects of the antibiotic sulfadiazine in soil ecosystems. TrAC Trends Anal. Chem., 28(5): 612-618.

Tabatabai M.A., 1994. Soil enzyme. In: Microbiological Biochem. Prop. (Eds R.W. Weaver, J.S. Angle, P.S. Bottomley). Soil Science Society of America. Madison, WI, USA.

Thiele-Bruhn S., 2005. Microbial inhibition by pharmaceutical antibiotics in different soils-dose-response relations determined with the iron (III) reduction test. Environ. Toxicol. Chem., 24(4): 869-876.

Thiele-Bruhn S. and Beck I.-C., 2005. Effects of sulfonamide and tetracycline antibiotics on soil microbial activity and microbial biomass. Chemosphere, 59(4): 457-465.

Widenfalk A., Svensson J.M., Goedkoop W., 2004. Effects of the pesticides captan, deltamethrin, isoproturon, and pirimicarb on the microbial community of a freshwater sediment. Environ. Toxicol. Chem., 23(8): 1920-1927.

Wu N., Qiao M., Zhang B., Cheng W.-D., and Zhu Y.-G., 2010. Abundance and diversity of tetracycline resistance genes in soils adjacent to representative swine feedlots in China. Environ. Sci. Technol., 44(18): 6933-6939.

Xiu-Mei L.I.U., Qi L.I., Liang W.-J., and Jiang Y., 2008. Distribution of Soil Enzyme Activities and Microbial Biomass Along a Latitudinal Gradient in Farmlands of Songliao Plain, Northeast China. Pedosphere, 18: 431-440.

Yao X., Min H., Lü Z., and Yuan H., 2006. Influence of acetamiprid on soil enzymatic activities and respiration. Eur. J. Soil Biol., 42(2), 120-126.

Zhang Y., Xu J., Zhong Z., Guo C., Li L., He Y., Fan W., and Chen Y., 2013. Degradation of sulfonamides antibiotics in lake water and sediment. Environ. Sci. Pollut. Res., 20(4): 2372-2380. 